\title{
A Decolonized Mood of Creating a Three-dimensional Digital Space Based on Integrating Transdisciplinary Knowledge
}

\author{
Keywords \\ Digital art, Virtual Reality in Education, 3D Computer Graphics Programming, \\ Lifelong learning, Coding and visual literacy.
}

This experimental artwork has attempted to produce a decolonized mood of researching and creating Three-dimensional (3D) Virtual Reality (VR) digital spaces based on using and integrating transdisciplinary knowledge. These research and creative 3DVR digital spaces processes have been connected with applying the concept of Digital Transformation (DX) within Educative Computational Practice (ECP) proceedings, addressing the idea of empowering people. The mentioned ECP proceedings have occurred through designing and carrying out 3DVR digital spaces by using 3D computer graphics programming techniques, bringing about individuals' developing digital and visual communication skills with support of employing Web3D-based technologies, such as the Extensible 3D (X3D) language and the X3Dom framework, as Open Educational Resources (OER). Low cost and accessible Web3D technologies have allowed practicing, analyzing and extending our open-ended long-term investigation at K-12 education levels referent to sharing 3DVR and computer graphics programming knowledge, aiming to inspire individuals' engagement in computing practices encompassing coding and visual literacy skills. These educational processes have also been sustained by art and its learning and expressing opportunities in the digital age. With support of Web3D technologies and lifelong learning and teaching experiences, we have taken part of a course called "Projeto Espetáculo em Realidade Aumentada", at Fabrica de Cultura Diadema. Through this course, there has been designed and implemented a 3DVR artwork which has extended our research and digital knowledge acquisition processes through producing a decolonized content by interconnecting conceptual knowledge referent to the visual artwork of Rubem Valentim's mix of Afro-Brazilian, Amerindian and European cultures and Jacob Lawrence's Afro-American culture symbolic representation. Both artists have trajectories of lifelong learning and using geometry and colorful forms in their artwork composition. Their artwork has expressed knowledge related to Afro-Brazilian and Afro-American cultures, contributing to reduce a gap, at official education, in the teaching of black culture contributions to the worlds of arts, sciences and technology. Interacting with these artists' trajectories and artworks has led to research, apply and share knowledge related to ancient Africa, having as reference the Egyptian civilization use of mathematics, geometry (at some extent sacred geometry) shapes and colors knowledge for building and decorating pyramids and other monuments. Such transdisciplinary knowledge confluence has made part of researching and forming the bases of computer graphics libraries and techniques in databases, allowing through educative $3 \mathrm{D}$ computer programming practices, to integrate in this 3DVR artwork features referent to digital sculpture, installation and net art, be it within a standalone way and/or through a blog-based interface online. This knowledge confluence has brought about using 3D computer graphics programming proceedings for building and visualizing symbolic representation of Afro-Brazilian, European and Amerindian Enchanted Beings' sacred adornments and instruments. It includes, based on the artwork another Brazilian educator and artist, Abdias do Nascimento, learning to research and utilize knowledge from people of the West Africa related to a writing system, the Adinkra, which is a group of symbols that express and represent ideas in proverbs. In addition, this artwork participatory development has stimulated individuals enhancing cognitive and technical skills, including their complex and spatial thinking abilities. 